\title{
AUTO DEL TRIBUNAL CONSTITUCIONAL
}

\section{VISTO:}

El pedido de nulidad "ipso iure" del auto de fecha 5 de abril de 2016, presentado por Carlos Baltazar Tapia, abogado de Humberto Bocanegra Chávez, recibido con fecha 6 de marzo de 2017; y,

\section{ATENDIENDO A QUE:}

1. El peticionante solicita que se declare la nulidad del auto de fecha 5 de abril de 6, emitido por este órgano colegiado, alegando que al Tribunal Constitucional "no le asiste ninguna atribución para alterar, modificar, o corregir los votos y texto de la referida sentencia [de fecha 14 de junio de 2013]".

2. Al respecto, como fue señalado en el propio auto de fecha 5 de abril de 2016, el artículo 121 del Código Procesal Constitucional prevé la competencia de este Tribunal "para aclarar algún concepto o subsanar cualquier error material $u$ omisión en que hubiese incurrido sus resoluciones". Y es en el ejercicio de dicha potestad correctora que este Tribunal Constitucional subsanó el error material detectado en la sentencia de junio de 2013, en la cual se incorporó indebidamente un fundamento y un punto resolutorio, por no contar con los votos necesarios para ello, tal cual fue suficientemente explicado entre los fundamentos 8 al 13 de nuestro auto del 5 de abril de 2016.

3. Debe tenerse en cuenta, asimismo, que quienes presentaron en su momento las solicitudes de subsanación o nulidad en ningún momento pidieron que ser admitidos como partes o partícipes, sino que únicamente pusieron en conocimiento del Tribunal los vicios que detectaron, con la finalidad de que el órgano colegiado emita un 
pronunciamiento de oficio, forma de actuación del Tribunal que constitucionalmente está habilitada en este tipo de situaciones. Además, conforme a los cargos de notificación que obran en los actuados, la sentencia de 2013 fue notificada entre los días 6 y 16 de setiembre de ese mismo año, por lo que no es cierto que se trató de un pedido extemporáneo, conforme se verifica a fojas 80 del cuadernillo del Tribunal Constitucional (pedido de aclaración de fecha 16 de setiembre de 2013).

4. Por otra parte, tal y como se ha dado cuenta en otras ocasiones (por ejemplo en los votos singulares de los casos ATC $N^{\circ}$ 04617-2012-AAReposición y ATC $N^{\circ}$ 03700-2013-AA-Nulidad, el voto dirimente de la STC N 02135-2012-PA, las resoluciones RTC Exp. N 02135-2012-AANulidad, RTC Exp. $N^{\circ}$ 2046-2011-HC/TC-Reposición, RTC Exp. $N^{\circ}$ 02488-2011-HC/TC-Nulidad, RTC Exp. N00705-2011-AA-Nulidad, RTC Exp. $\quad \mathrm{N}^{\circ}$ 03681-2010-HC/TC-Nulidad, RTC Exp. $\mathrm{N}^{\circ}$ 00831-2010PHD/TC-Nulidad, RTC Exp. N²023-2010-AA/TC-Nulidad, RTC Exp. $\mathrm{N}^{\circ}$ 4104-2009-AA/TC, RTC Exp. N 02386-2008-AA/TC-Nulidad, RTC Exp. N 06348-2008-AA Resolución (RTC 8230-2006-AA), RTC Exp. N ${ }^{\circ}$ 00978-2007-AA/TC, RTC Exp. No 04324-2007-AC-nulidad, RTC Exp. N 5314-2007-PA/TC-Nulidad, RTC Exp. N 03992-2006-C, o como también se ha resuelto recientemente en la ATC $\mathrm{N}^{\circ}$ 03982-5-HC-Aclaracion), el Tribunal Constitucional puede decidir, de modo excepcional, la nulidad de sus propias decisiones sobre la base de ciertos supuestos de vicios graves e irremediables. Al respecto, precisamente, en el fundamento 6 de la resolución ahora cuestionada se señala en qué supuestos el Tribunal Constitucional está habilitado para, cuando corresponda, declarar la nulidad de sus propias decisiones. Conforme a las mencionadas pautas, esto puede hacerse frente a vicios graves de procedimiento, vicios o errores graves de motivación, y vicios sustantivos contra el orden jurídico-constitucional.

5. En el presente caso, debido a que la resolución de subsanación no ha incurrido en alguno de los vicios señalados, corresponde declarar improcedente el pedido de nulidad formulado.

6. Por estas consideraciones, el Tribunal Constitucional, con la autoridad que le confiere la Constitución Política del Perú, con el fundamento de voto del magistrado Carlos Ramos Núñez que se agrega,

\section{RESUELVE}

Declarar IMPROCEDENTE el pedido de nulidad. 
Publíquese y notifíquese.

SS.

MIRANDA CANALES

LEDESMA NARVÁEZ

RAMOS NÚÑEZ

ESPINOSA-SALDAÑA BAR

\section{FUNDAMENTO DE VOTO DEL MAGISTRADO RAMOS NÚÑEZ}

Emito el presente fundamento de voto a fin de efectuar una serie de consideraciones adicionales a las ya expuestas por mis pares.

Mediante escrito de fecha 6 de marzo de 2017, Sergio Carlos Baltazar Tapia Tapia solicita la "nulidad ipso iure" del auto publicado por este Tribunal el 3 de marzo de 2017, en el cual se resolvió subsanar la sentencia de fecha 14 de junio de 2013, y, por ende, tener por no incorporados en la resolución el fundamento 68 y el punto 1 de la parte resolutiva.

Sus argumentos, en esencia, radican en que la resolución que expidió este Tribunal afectaría la estabilidad jurídica de la cosa juzgada. Refiere que la nulidad es una consecuencia jurídica, y que, sin embargo, ha sido declarada sin que se presente algún hecho o se haya practicado algún acto que la amerite. También agrega que dicho pronunciamiento se realizó sin que nadie que haya sido parte en el proceso lo solicite. Finalmente, sostiene que lo que ocasiona la resolución expedida es que se creen dos instancias dentro del propio Tribunal Constitucional.

Nuestra resolución, al resolver dicho pedido, ha expuesto, de manera detallada, una serie de supuestos en los que es posible revisar, por la presencia de ciertos vicios, nuestras propias decisiones. Entiendo, sin embargo, que no se trata de una situación cotidiana; por el contrario, su uso debe ser excepcional y limitarse para aquellos casos en los que verdaderamente se pueda comprometer el orden constitucional. En otra oportunidad tuve la oportunidad de señalar que, para que ello ocurra, debíamos encontrarnos ante un vicio de considerable magnitud y trascendencia [Cfr. fundamento de voto en la STC $\mathrm{N}^{\circ}$ 04617-2012-P/TC]. Estimo, como se indicó en el auto de fecha 5 de abril de 2016, que, en este caso, el erróneo conteo de votos sí justifica esta clase de pronunciamientos, por cuanto no se ha respetado la propia voluntad del Tribunal que, en aquel entonces, se pronunció sobre el pedido de nulidad del 
auto apertura de instrucción en el expediente $N^{\circ}$ 2007-00213-01801-JR-PE-04. En ese sentido, la solicitud presentada solo estaba direccionada a cuestionar los argumentos expuestos en nuestra resolución, lo cual no es viable en esta clase de pedidos.

El Tribunal resolvió, por mayoría, no tener por incorporado ni el fundamento $68 \mathrm{ni}$ el punto resolutivo 1 de la sentencia de 14 de junio de 2013. En distintos fueros y medios de comunicación ello ha sido advertido como una supuesta usurpación de las labores del Poder Judicial, ya que la consecuencia de nuestro pronunciamiento sería alterar la naturaleza de la cosa juzgada y, de ese mismo modo, la seguridad jurídica. No son correctas tales afirmaciones.

Nuestro pronunciamiento detectó un vicio de forma en el conteo de votos que afectaba la parte resolutiva. Advertir dicha situación no es, de ninguna manera, alterar el fondo de una sentencia emanada de una autoridad competente; antes bien, es una forma de protegerla. No hemos desarrollado argumentos en el sentido de cuestionar la figura de la eventual imprescriptibilidad de los delitos denunciados, sino que nos hemos ceñido a hacer notar cómo el erróneo conteo de votos alteró la esencia el sentido de la sentencia del Pleno del Tribunal de aquella época.

Por ello, sostener que mis colegas y yo estamos asumiendo funciones que no nos competen es desconocer el sentido de nuestro pronunciamiento. Los pedidos que se hicieron llegar a nuestra instancia nunca impugnaron directamente el fondo de lo resuelto por el Tribunal en esa oportunidad Lo que sí se hizo fue poner en nuestro conocimiento la existencia de un vicio de forma que debía ser subsanado a fin de respetar la voluntad de los magistrados que suscribieron la sentencia del 14 de junio de 2013. Esta precisión era fundamental.

Nuestra jurisprudencia ha reconocido, en reiteradas oportunidades, que las resoluciones judiciales deben ser ejecutadas en sus propios términos [STC $\mathrm{N}^{\circ}$ 01797-2010-PA/TC, fundamento 7; 00246-2012-PA/TC, fundamento 2; 085042013-PA/TC, fundamento 4; 02382-2012-PA/TC, fundamento 7], y esta garantía también abarca, claro está, a las decisiones que emite este Tribunal. Esta expresión se encuentra estrechamente ligada con el hecho que las resoluciones judiciales deban ser interpretadas en su integridad, lo cual guarda una importante conexión con el derecho a la tutela procesal efectiva. Ignorar esta situación supondría no solo alterar el sentido del fallo, sino también perjudicar a las partes procesales. 
Finalmente, deseo resaltar que la labor de este Tribunal siempre ha estado orientada a combatir todos aquellos flagelos que subviertan las premisas esenciales del Estado Constitucional. De hecho, la propia sentencia de 14 de junio de 2013, en una reflexión que comparto íntegramente, había demostrado esta preocupación al precisar que no podemos ser ajenos a la violencia vivida por nuestro país durante los años 80 del pasado siglo, por lo que se considera pertinente reiterar la posición institucional expresada en la sentencia recaída en el proceso de inconstitucionalidad llevado contra la legislación antiterrorista. En ese sentido, no cabe sino reafirmar que la acción terrorista en nuestro país se convirtió en la lacra más dañina para la vigencia plena de los derechos fundamentales de la persona y para la consolidación promoción de los principios y valores de un Estado democrático [...] [STC N 01969-20 fundamento 12].

Nos encontramos comprometidos con esa misión. La violencia, sea cual fuere su fuente, debe ser completamente proscrita. Nuestro desarrollo como sociedad depende de que esa sea una pauta de convivencia que debemos tomar en serio.

S.

RAMOS NÚÑEZ 